\title{
COVID-19: An Insight Into the Pandemic of a New Emerging Coronavirus
}

\author{
Olusola A. Akanbi, Oluyinka O. Opaleye*, Adekunle O. Olowe, Olusola \\ Ojurongbe
}

\author{
Department of Medical Microbiology and Parasitology, Ladoke Akintola Univer- \\ sity of Technology, Osogbo, Osun State Nigeria
}

Correspondence should be addressed to : ooopaleye@lautech.edu.ng

Received 20 March 2020; Revised 21 March 2020; Accepted 21 March 2020

(C) 2020 Akanbi et al. Licensee Pan African Journal of Life Sciences. This is an Open Access article distributed under the terms of the Creative commons Attribution License (https://creativecommons.org/ licenses/BY/4.0), which permits unrestricted use, distribution, and reproduction in any medium, provided the original work is properly cited.

Background: Since December 2019, a novel Coronavirus named Severe Acute Respiratory Syndrome Coronavirus 2 (SARS-CoV-2) has been implicated in an outbreak of SARSlike illness, which began in a wild animal market of Wuhan in Hubei province of China and the World Health Organization (WHO) was alerted on the 31st December 2019 of this public health threat. On the 11th March 2020, the WHO announced that this disease termed COVID-19 has become pandemic, the first for any coronavirus. Coronaviruses are a large family of viruses that cause illness such as the common cold to more severe diseases such as SARS. To date, the virus has spread to over 100 countries, including 40 countries in Africa, including Nigeria. As at the time of this publication over 300,000 cases has been reported world-wide with over 14,000 deaths mostly from China and Italy. The Nigerian Centre for Disease Control (NCDC) has since put in place measures to contain and prevent the further spread of the virus. This review highlights the current situation and knowledge of the newly emerged SARS-CoV-2 and its epidemiological trends.

Keywords: SARS-CoV-2, Coronaviruses, COVID-19, Pandemic 


\section{1.o INTRODUCTION}

Coronaviruses (CoVs) infect a wide range of vertebrates, such as bats, snakes, birds, humans, and other wild animals $[1,2]$. They are broadly divided into two based on their virulence; the low pathogenic CoVs and the highly pathogenic CoVs [3]. Before December 2019, there were six known CoVs which cause disease in humans. Four are classified as low pathogenic CoVs namely the HCoV-229E, HCoV-HKU1, HCoV-OC43 and HCoV-NL63, which are responsible for approximately $15 \%$ of common colds. The remaining two are highly pathogenic CoVs including Severe Acute Respiratory Syndrome (SARS) and the Middle East Respiratory Syndrome (MERS) CoVs which mainly infect the lower respiratory tracts causing fatal pneumonia with high mortality rates in humans $[2,4]$.

In December 2019, a novel CoV now designated the SARS -CoV-2 by the International Committee of Taxonomy of Viruses (ICTV) emerged in the city of Wuhan, China causing an outbreak of a SARS-like illness [5-7]. The coronavirus disease 2019 (COVID-19) was first reported to the World Health Organization (WHO) on 31st December 2019 [8]. The novel SARS-CoV-2, currently believed to have originated from wild animals specifically bats, and now with evidence of human-to-human transmissions, have spread across the cities or territories in China and internationally to all the continents of the world (Figure 1) with cases reported in 168 countries as at 19th March 2020 [9]. In the space of fewer than three months, the COVID-19 has been responsible for over 300,000 cases and 14,000 deaths worldwide mostly from China and Italy with up to $3.5 \%$ mortality [10] as at the time of this publication, and the figure keep rising.

On 3oth January 2020, the WHO declared the outbreak of COVID-19 as a Public Health Emergency of International Concern, posing a high risk to countries with vulnerable health systems [11]. On the 11th March, 2020, COVID-19 was declared as a pandemic, the first for any coronavirus [12]. On the 27th February 2020, the first case of the novel COVID-19 infection was reported in Nigeria as an imported case from an Italian returning back to work in Nigeria. On the 9th March, a second case was confirmed, which was a contact linked to the index case and by 22nd March, the total cases in Nigeria have risen to thirty [13]. This review summarises the current knowledge on the COVID-19, its characteristics, and updates on the current epidemiological trends.

\section{2.o VIROLOGY}

Coronaviruses (CoVs) are enveloped, single-stranded RNA viruses belonging to the family Coronaviridae. SARS-CoV-2 identified on the 7th of January 2020 belongs to the subfamily Orthocoronavirinae and the genus betacoronavirus $[1,2,11]$. The genome of CoVs is a positive-strand RNA with sizes ranging from 26 to $32 \mathrm{~kb}$

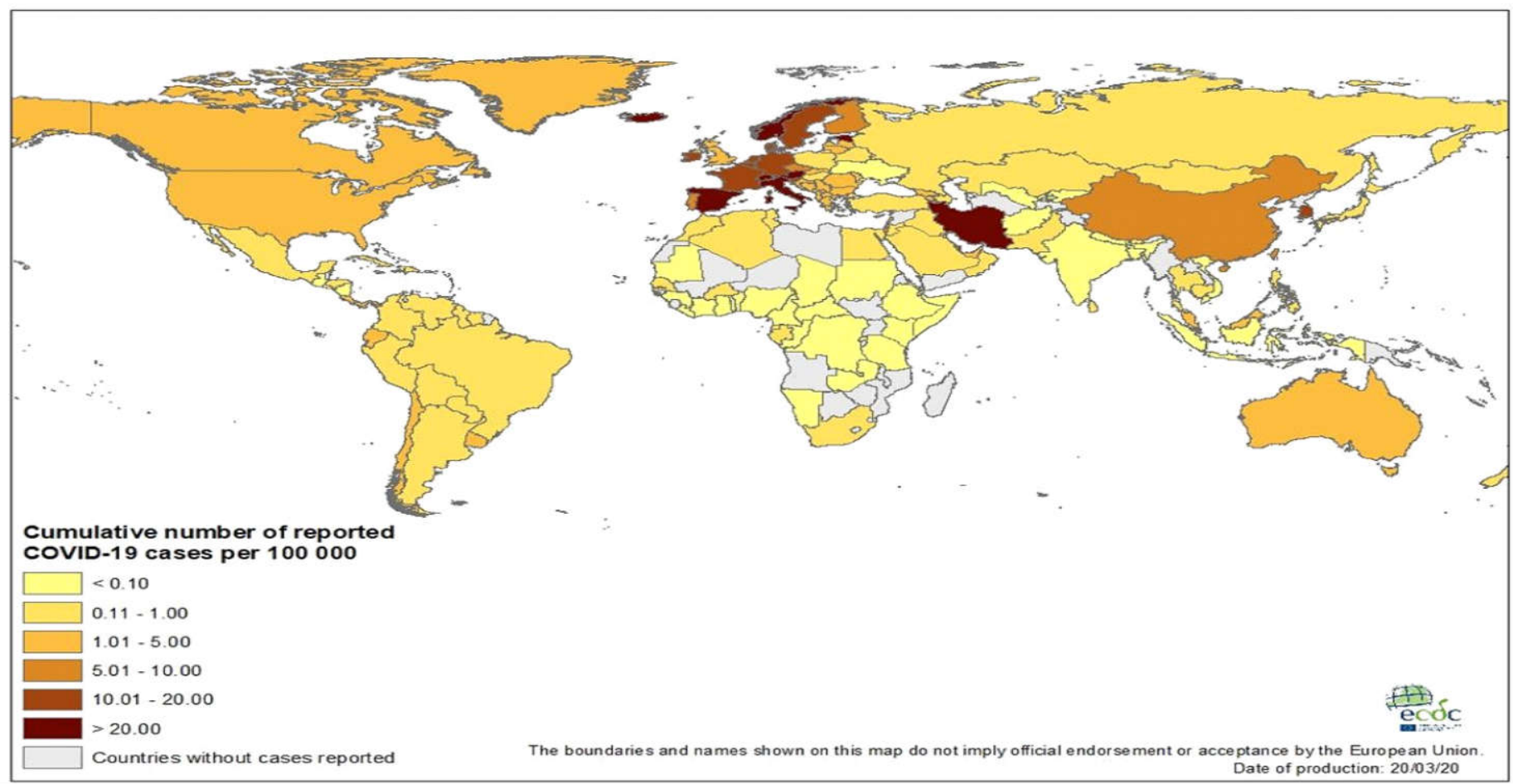

Figure 1: The worldwide distribution of cumulative Coronavirus cases as at 20th March 2020.

Source : https://www.ecdc.europa.eu/en/geographical-distribution-2019-ncov-cases 
in length, the largest among RNA viruses. The $\mathrm{CoV}$ particles are pleomorphic or spherical and range from 150 to $160 \mathrm{~nm}$ in size, with the genomic RNA, nucleoprotein, capsid, matrix, and S-protein associated [2] (Figure 2). Although SARS-CoV-2 shares $79 \%$ of its genome with SARS-CoV, it is more transmissible and also with lower case fatality rate, and the genome contains a novel orf8 [14]. Analysis of the full genome sequence shows that the SARS-CoV-2 is not a recombinant virus, but the novel $\mathrm{CoV}$ has higher nucleotide identity with bat including stool and blood [19], and can be transmitted by droplets and contact with infected people. Asymptomatic people also may be infectious $[17,20]$. It is not evident whether mother-to-child transmission of the virus is possible, however, care should be taken as new-borns as much as other age groups are susceptible to infection by the novel SARS-CoV-2 [17]. There are indication that SARS-CoV-2 may survive in the air in some settings for up to 8 hours. Ongoing studies are specifically investigating how humidity, temperature and ultraviolet

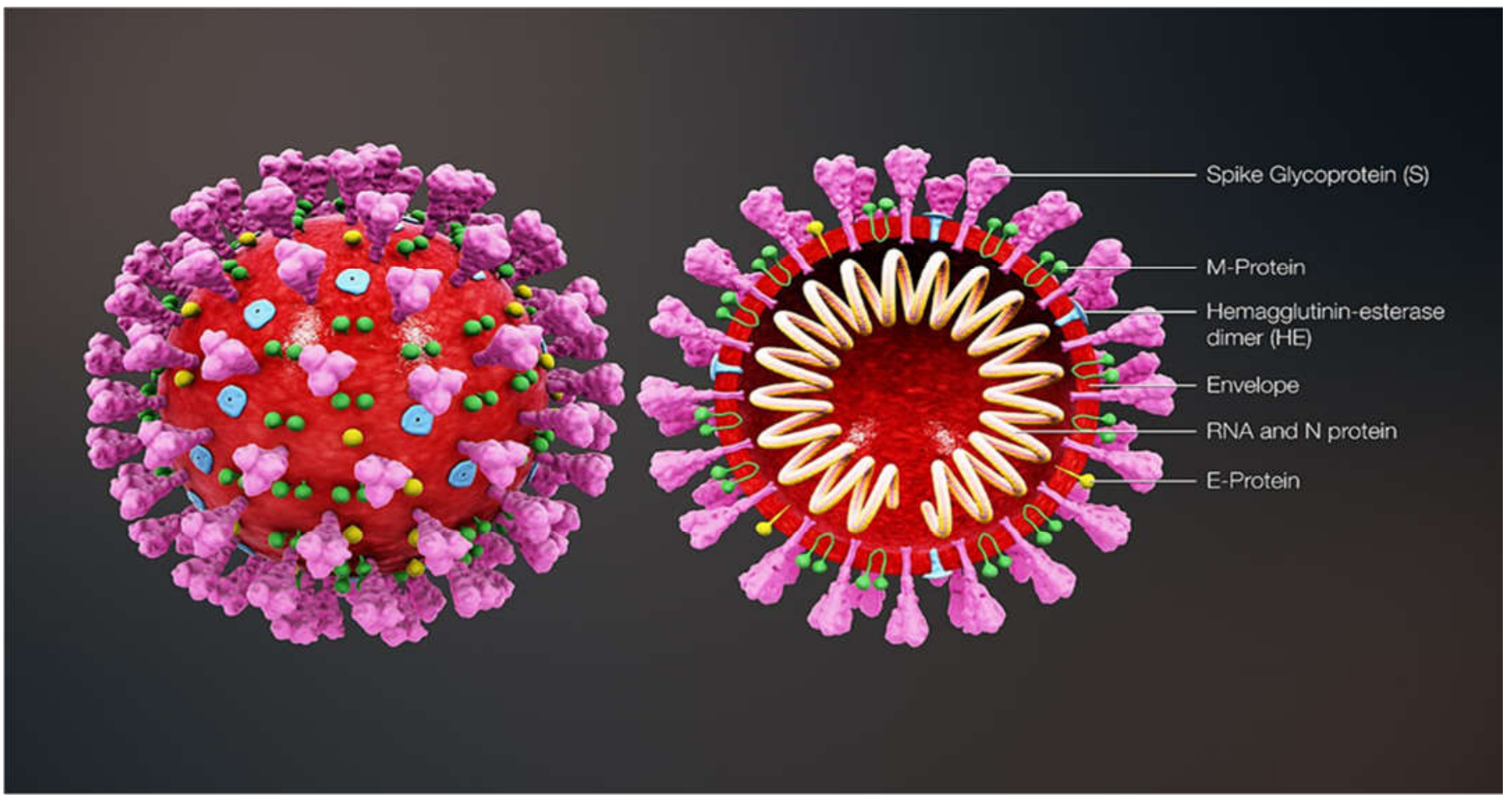

Figure 2: Three-dimensional medical illustration of 2019 Novel Coronavirus SARS-CoV-2

Source: https://www.scientificanimations.com/3d-medical-animation-still-shot-showing-coronavirus-structure/

SARS-like-CoV than with that of human SARS-CoV [3, 14]. The receptor-binding domain of the S-protein of SARS-CoV-2 is very similar to that of SARS-CoV in structure, however, with some differences in amino acid composition, suggesting that the human ACE2 could be the receptor for the entry of SARS-CoV-2 [15]. Also, the SARS-CoV-2 S protein bind to ACE2 with higher affinity than SARS-CoV S-protein $[3,8,16]$.

\section{O EPIDEMIOLOGY}

The SARS-CoV-2 has high pathogenicity and transmissibility, judging from how it has spread to over 100 countries in less than three months [17]. The mean incubation period for COVID-19 has been calculated to be 2-10 days, though it varies widely between individuals but on average of about five days [11, 18]. The virus is mostly shed in respiratory fluids of infected people; however, the virus can be detected in other specimens, lighting affects the virus as well as how long it lives on different surfaces, including steel.

COVID-19 is associated with mild symptoms such as dry cough, sore throat, and fever and in majority of cases there is spontaneously resolution of these symptoms. However, in some cases, various fatal complications such as organ failure, septic shock, pulmonary oedema, severe pneumonia, and Acute Respiratory Distress Syndrome (ARDS) has been recorded [11]. Older adults and people with severe underlying chronic medical conditions such as heart or lung disease or diabetes seem are at higher risk for developing these serious complications [21].

\section{4.o PATHOGENESIS}

The detail of the pathogenesis of COVID-19 is yet to be fully understood, however, it is thought to have a similar course to that of SARS and MERS. As a virus whose main target is the respiratory system, severe pneumonia, 
RNAaemia, combined with the incidence of ground-glass opacities, and acute cardiac injury are the main features [22]. Reports show that COVID-19 patients showed higher leukocyte numbers, abnormal respiratory findings, and increased levels of plasma pro-inflammatory cytokines [23]. There is also a significantly high level of circulating cytokines and chemokines in some patients. Some of the severe cases that were admitted in intensive care showed high levels of pro-inflammatory cytokines such as IL2, IL7, IL10, GCSF, IP10, MCP1, MIP1a, and TNFa which are believed to contribute to disease severity [22, 24].

\subsection{CLINICAL SYMPTOMS}

COVID-19 has an incubation period of approximately 5 days after which symptoms begin to appear. It has been estimated that the time between the onset of symptoms and death in infected people is between 6 to 41 days and 14 days on the average [25]. This however, depends on other host factors such as the age of the patient at infection and the immune status, as people above 70 years of age tend to have a more fatal outcome compared to those younger [23]. The most frequent presenting symptoms in COVID-19 patients at the onset include fever, dry cough, shortness of breath, myalgia, fatigue and others such as sputum production, headache, pharyngalgia and diarrhoea in few patients $[22,26]$. Patients with severe outcomes developed acute respiratory distress syndrome (ARDS) and most of them required transfer to an intensive care unit (ICU). Deaths occurred due to multiple organ failure [21, 23, 27, 28].

Some extra-pulmonary features seen in patients include abdominal disorders, nausea, vomiting, diarrhoea, and acute renal failure. Other clinical findings also found are; increase in white blood cells, mainly neutrophils, and decrease in lymphocytes, platelets, and red blood cells [29]. Half of the patients showed comorbidities (hypertension, cardiovascular disease and diabetes). Infection with COVID-19 virus has not been commonly diagnosed in children so far and the few infected have a mild form of the disease [30]. COVID-19 has severe outcomes in the elderly, people with underlying health conditions and pregnant women. The disease has been shown to be associated with preterm births or miscarriages in pregnant women infected late in pregnancy. However there is no sufficient data to suggest vertical transmission of the disease [31, 32].

\section{6.o DIAGNOSIS}

The WHO has recommended that the decision to test should be based on clinical and epidemiological factors and linked to an assessment of the likelihood of infection [17]. Samples for testing should also be collected as soon as possible, and testing of appropriate specimens from patients meeting the suspect case definition for COVID19 is a priority for clinical management and outbreak control, which should be guided by a laboratory expert.

Specimens to be collected include nasopharyngeal and oropharyngeal swab or wash in ambulatory patients and/ or sputum (if produced) and or endotracheal aspirate or bronchoalveolar lavage in patients with more severe respiratory disease. Additional clinical specimens such as blood or stool may be collected as the COVID-19 virus has been detected in blood and stool [19]. Patients showing clinical signs such as fever and or respiratory tract symptoms, radiographic evidence, low or normal white-cell count or low lymphocyte count in the early period, and those with an epidemiological history, consistent with any two clinical features, are diagnosed as suspected cases. Suspected cases should be confirmed using nucleic acid amplification tests (NAAT), such as rRT-PCR by targeting a consensus $\mathrm{E}$ region of pan beta- $\mathrm{CoV}$ or other more specific regions (such as $\mathrm{RdRp}$ or $\mathrm{N}$ region) followed by nucleic acid sequencing when necessary [3]. RNA extraction should be carried out in a biosafety cabinet in a BSL-2 or equivalent facility, but for viral culture up to BSL-3, however, viral culture is not required for routine laboratory diagnosis [33]. Serological tests for COVID-19 are currently under development, although a significant challenge may be the possibility of crossreactivity with other CoVs.

\subsection{TREATMENT}

There is currently no specific effective antiviral treatment or vaccine for COVID-19, so treatment involves symptomatic and supportive care. These include bed rest, adequate nutrition, prevention of dehydration and maintaining water, electrolyte, and acid-base balance, keeping vital signs, maintaining oxygen saturation and blood pressure, and treating complications, such as secondary infections or organs failure in patients with severe infections $[4,11]$. Alpha-interferon and lopinavir/ritonavir have been suggested for treatment, however, due to the high transmissibility and mortality of COVID-19, many antiviral therapy options are undergoing investigation which include; Remdesivir: ribavirin and Convalescent therapies $[28,34]$. Favilavir, formerly known as Fapilavir, initially licensed for use against CoVs may also be a valuable drug [4]. Chloroquine, an antimalarial drug has also been found to be inhibit SARS-CoV-2 in-vitro. Chloroquine has been found to be active against several viral infections however with little successes, but recent data suggest it may be useful in treating COVID-19 patients however clinical trials are on-going [35, 36]. 


\section{8.o CONTROL AND PREVENTION}

There is currently no vaccine available for preventing 2019-nCoV infection. The spike protein may serve as a vaccine candidate, but the effect on humans requires further evaluation. The limitation of the spread of the virus is the current strategy for prevention, and it focuses on; early case detection and diagnosis, rigorous infection control, animal source containment, timely case report and rapid information dissemination [4]. For the general public, the WHO has issued the following recommendations:

1. Avoid close contact with subjects suffering from acute respiratory infections.

2. Wash your hands frequently with alcohol-based sanitizers and soaps, especially after contact with infected people or their environment.

3. Avoid unprotected contact with farm or wild animals.

4. People with symptoms of acute airway infection should keep their distance, cover coughs or sneezes with disposable tissues or clothes and wash their hands.

5. Strengthen, in particular, in emergency medicine departments, the application of strict hygiene measures for the prevention and control of infections.

6. Individuals that are immunocompromised should avoid public gatherings [34, 37].

\section{References}

1. Ashour HM, Elkhatib WF, Rahman MM, Elshabrawy HA. Insights into the Recent 2019 Novel Coronavirus (SARSCoV-2) in Light of Past Human Coronavirus Outbreaks. Pathog Basel Switz. 2020;9.

2. Su S, Wong G, Shi W, Liu J, Lai ACK, Zhou J, et al. Epidemiology, Genetic Recombination, and Pathogenesis of Coronaviruses. Trends Microbiol. 2016;24:490-502.

3. Wu Y-C, Chen C-S, Chan Y-J. The outbreak of COVID-19: An overview. J Chin Med Assoc. 2020;83:217-220.

4. Yang Y, Peng F, Wang R, Guan K, Jiang T, Xu G, et al. The deadly coronaviruses: The 2003 SARS pandemic and the 2020 novel coronavirus epidemic in China. J Autoimmun. 2020;:102434.

5. Cheng ZJ, Shan J. 2019 Novel coronavirus: where we are and what we know. Infection. 2020. doi:10.1007/s15010020-01401-y.

6. Coronaviridae Study Group of the International Committee on Taxonomy of Viruses. The species Severe acute respiratory syndrome-related coronavirus: classifying 2019-nCoV and naming it SARS-CoV-2. Nat Microbiol. 2020.

7. Wang C, Horby PW, Hayden FG, Gao GF. A novel coronavirus outbreak of global health concern. Lancet Lond Engl. 2020;395:470-3.
8. Lu H, Stratton CW, Tang Y-W. Outbreak of pneumonia of unknown etiology in Wuhan, China: The mystery and the miracle. J Med Virol. 2020;92:401-2.

9. World Health Organisation. Coronavirus. 2020. https:// www.who.int/emergencies/diseases/novel-coronavirus2019. Accessed 20 Mar 2020.

10. Novel coronavirus (COVID-19) situation. 2020. https:// experience.arcgis.comexperience/685doace 521648f8a5 beeeee1b9125cd. Accessed 20 Mar 2020.

11. Sohrabi C, Alsafi Z, O’Neill N, Khan M, Kerwan A, Al-Jabir A, et al. World Health Organization declares global emergency: A review of the 2019 novel coronavirus (COVID-19). Int J Surg Lond Engl. 2020;76:71-6.

12. WHO Director-General's opening remarks at the media briefing on COVID-19 - 11 March 2020. 2020. https:// www.who.int/dg/speeches/detail/who-director-general-sopening-remarks-at-the-media-briefing-on-covid-19---11march-2020. Accessed 20 Mar 2020.

13. NCDC Covid-19 Page. http://covid19.ncdc.gov.ng/. Accessed 20 Mar 2020.

14. Chan JF-W, Kok K-H, Zhu Z, Chu H, To KK-W, Yuan S, et al. Genomic characterization of the 2019 novel humanpathogenic coronavirus isolated from a patient with atypical pneumonia after visiting Wuhan. Emerg Microbes Infect. 2020;9:221-36.

15. Hoffmann M, Kleine-Weber $\mathrm{H}$, Schroeder S, Krüger $\mathrm{N}$, Herrler T, Erichsen S, et al. SARS-CoV-2 Cell Entry Depends on ACE2 and TMPRSS2 and Is Blocked by a Clinically Proven Protease Inhibitor. Cell. 2020.

16. Wrapp D, Wang N, Corbett KS, Goldsmith JA, Hsieh C-L, Abiona O, et al. Cryo-EM structure of the 2019-nCoV spike in the prefusion conformation. Science. 2020;367:1260-3.

17. Han Y, Yang H. The transmission and diagnosis of 2019 novel coronavirus infection disease (COVID-19): A Chinese perspective. J Med Virol. n/a n/a. doi:10.1002/jmv.25749.

18. Lauer SA, Grantz KH, Bi Q, Jones FK, Zheng Q, Meredith $\mathrm{HR}$, et al. The Incubation Period of Coronavirus Disease 2019 (COVID-19) From Publicly Reported Confirmed Cases: Estimation and Application. Ann Intern Med. 2020.

19. Holshue ML, DeBolt C, Lindquist S, Lofy KH, Wiesman J, Bruce H, et al. First Case of 2019 Novel Coronavirus in the United States. N Engl J Med. 2020;382:929-36.

20. Rothe C, Schunk M, Sothmann P, Bretzel G, Froeschl G, Wallrauch $\mathrm{C}$, et al. Transmission of 2019-nCoV Infection from an Asymptomatic Contact in Germany. N Engl J Med. 2020;382:970-1.

21. Jiang F, Deng L, Zhang L, Cai Y, Cheung CW, Xia Z. Review of the Clinical Characteristics of Coronavirus Disease 2019 (COVID-19). J Gen Intern Med. 2020. doi:10.1007/s11606020-05762-w.

22. Huang C, Wang Y, Li X, Ren L, Zhao J, Hu Y, et al. Clinical features of patients infected with 2019 novel coronavirus in Wuhan, China. Lancet Lond Engl. 2020;395:497-506.

23. Rothan HA, Byrareddy SN. The epidemiology and pathogenesis of coronavirus disease (COVID-19) outbreak. J Autoimmun. 2020;:102433.

24. Zhu N, Zhang D, Wang W, Li X, Yang B, Song J, et al. A 
Novel Coronavirus from Patients with Pneumonia in China, 2019. N Engl J Med. 2020;382:727-33.

25. Wang W, Tang J, Wei F. Updated understanding of the outbreak of 2019 novel coronavirus (2019-nCoV) in Wuhan, China. J Med Virol. 2020;92:441-7.

26. Ren L-L, Wang Y-M, Wu Z-Q, Xiang Z-C, Guo L, Xu T, et al. Identification of a novel coronavirus causing severe pneumonia in human: a descriptive study. Chin Med J (Engl). 2020.

27. Brüssow H. The Novel Coronavirus - A Snapshot of Current Knowledge. Microb Biotechnol. n/a n/a. doi:10.1111/1751-7915.13557.

28. Han Q, Lin Q, Jin S, You L. Coronavirus 2019-nCoV: A brief perspective from the front line. J Infect. 2020. doi:10.1016/j.jinf.2020.02.010.

29. Meo SA, Alhowikan AM, Al-Khlaiwi T, Meo IM, Halepoto $\mathrm{DM}$, Iqbal M, et al. Novel coronavirus 2019-nCoV: prevalence, biological and clinical characteristics comparison with SARS-CoV and MERS-CoV. Eur Rev Med Pharmacol Sci. 2020;24:2012-9.

3o. Wei M, Yuan J, Liu Y, Fu T, Yu X, Zhang Z-J. Novel Coronavirus Infection in Hospitalized Infants Under 1 Year of Age in China. JAMA. 2020. doi:10.1001/jama.2020.2131.

31. Chen Y, Peng H, Wang L, Zhao Y, Zeng L, Gao H, et al. Infants Born to Mothers With a New Coronavirus (COVID-
19). Front Pediatr. 2020;8. doi:10.3389/fped.2020.00104.

32. Mullins E, Evans D, Viner RM, O’Brien P, Morris E. Coronavirus in pregnancy and delivery: rapid review. Ultrasound Obstet Gynecol. n/a n/a. doi:10.1002/uog.22014.

33. Technical guidance. 2020. https://www.who.int/ emergencies/diseases/novel-coronavirus-2019/technicalguidance. Accessed 20 Mar 2020.

34. Cascella M, Rajnik M, Cuomo A, Dulebohn SC, Di Napoli R. Features, Evaluation and Treatment Coronavirus (COVID19). In: StatPearls. Treasure Island (FL): StatPearls Publishing; 2020. http://www.ncbi.nlm.nih.gov/books/ NBK554776/. Accessed 20 Mar 2020.

35. Touret F, de Lamballerie X. Of chloroquine and COVID-19. Antiviral Res. 2020;177:104762.

36. Wang M, Cao R, Zhang L, Yang X, Liu J, Xu M, et al. Remdesivir and chloroquine effectively inhibit the recently emerged novel coronavirus (2019-nCoV) in vitro. Cell Res. 21 ○20;30:269-71.

37. Lai C-C, Shih T-P, Ko W-C, Tang H-J, Hsueh P-R. Severe acute respiratory syndrome coronavirus 2 (SARS-CoV-2) and coronavirus disease-2019 (COVID-19): The epidemic and the challenges. International Journal of Antimicrobial Agents 2020; doi.org/10.1016/j.ijantimicag.2020.105924 